\title{
Recidivism Risk and Criminogenic Needs of Individuals Who Perpetrated Intimate Partner Sexual Violence Offenses
}

\author{
Brandon Sparks $^{\text {a }}$, Farron Wielinga ${ }^{a}$, Sandy Jung ${ }^{b}$, Mark E. Olver ${ }^{a}$ \\ [a] Department of Psychology, University of Saskatchewan, Saskatoon, SK, Canada. [b] Department of Psychology, \\ MacEwan University, Edmonton, AB, Canada.
}

Sexual Offending: Theory, Research, and Prevention, 2020, Vol. 15(1), Article e3713,

https://doi.org/10.5964/sotrap.3713

Received: 2020-02-27 • Accepted: 2020-04-24 • Published (VoR): 2020-07-22

Handling Editor: Martin Rettenberger, Centre for Criminology (Kriminologische Zentralstelle - KrimZ), Wiesbaden, Germany

Corresponding Author: Brandon Sparks, Department of Psychology, University of Saskatchewan, 9 Campus Drive, Arts 154, Saskatoon, Saskatchewan, Canada S7N 5A5. E-mail: brandon.sparks@usask.ca

\begin{abstract}
Despite the common occurrence of sexual violence in intimate partner violence (IPV) and its association with increased risk of intimate partner homicide, intimate partner sexual violence (IPSV) is often overlooked in the literature. As a result, little is known about risk factors that may be unique to IPSV perpetrators. The present study utilizes a police-reported sample to compare the risk/need profiles of 36 IPSV and 36 IPV perpetrators by creating theoretically meaningful risk composites as proxies for a number of the central eight risk/need areas posited by Andrews and Bonta (2010, https://doi.org/10.1037/a0018362). Results indicate that the risk/need profiles of the IPSV group are more severe than the IPV group, with higher scores in measures of substance abuse, relationship instability, sexual aggression, and mental health concerns. Potential implications for IPSV assessment and intervention at the level of policing and correctional programming are discussed, including the need for higher intensity treatments and the treatment of non-criminogenic needs.
\end{abstract}

\section{Keywords}

intimate partner violence, intimate partner sexual violence, risk factors, criminogenic needs, ODARA, SARA 


\section{Highlights}

- Perpetrators of IPSV have more severe risk/need profiles than those who commit IPV.

- Perpetrators of IPSV also demonstrate more mental health concerns than those who commit IPV.

- Higher intensity treatment programs for perpetrators of IPSV may be warranted.

- Future research may benefit from distinguishing perpetrators of IPSV and IPV.

Over the past two decades, there has been increased attention to intimate partner violence (IPV) in empirical literature and society. The pervasiveness of IPV in comparison to other forms of targeted violence, combined with research linking IPV victimization with increased future risk for intimate partner homicide, have provided an impetus to better understand and treat this group of individuals (Campbell et al., 2007). However, less is known about intimate partner sexual violence (IPSV), which has risen by $25 \%$ between 2011 and 2016 in Canada (Keighley, 2017). Such increases are notable given that the rate of sexual assaults in general have decreased across Canada by $9 \%$. Intimate partners have also been implicated in 19\% of all sexual assaults (Rotenburg, 2017). When examining IPSV among women whose partners have also physically assaulted them, rates are much higher and range from 28\% (Eby et al., 1995) to 68\% (McFarlane et al., 2005).

Research suggests that violence tends to be more severe and recurrent, and perpetration more coercive when the violence perpetrated by an intimate partner is sexual in nature. Compared to other victims of sexual violence, Culbertson and Dehle (2001) found that IPSV victims were exposed to greater degrees of physical violence. Similarly, other researchers found that individuals who had faced IPSV victimization experienced more physical trauma (Stermac et al., 2006) and more incidents of violence (Mahoney, 1999) when compared to those who have been sexually abused by non-partners. In addition to the severity of violence, other research has shown that those who perpetrated IPV and sexually abused their partners were more likely to use coercive methods than those who were not sexually violent (Bergen \& Bukovec, 2006).

Despite the criminalization of spousal sexual assault nearly three decades ago in Canada, the United States, and several European countries, IPSV has failed to garner the attention of forensic researchers. IPSV may be overlooked partly because it lies at the intersection of IPV and sexual violence, with many instances subsumed into one category of research or the other. Furthermore, past literature contains inconsistencies in definitions and measurements on what defines IPSV (Bagwell-Gray et al., 2015). Given that IPSV occurs in a unique and specific context, this perpetrator group warrants its own field of inquiry. However, given that specialized interventions have not been developed to address IPSV perpetration, it is likely that, in practice, binary decisions 
are made to treat these individuals as either those who have perpetrated partner abuse or sexual offenses. For example, in the assessment of recidivism risk, practitioners may likely employ a risk assessment instrument that captures either risk for partner abuse (e.g., the Ontario Domestic Assault Risk Assessment [ODARA]; Hilton et al., 2010) or sexual violence (e.g., the Violence Risk Scale: Sexual Offender version [VRS-SO]; Wong et al., 2003). In addition, when interventions are considered, it is likely that individuals are placed into either an IPV treatment program or a sexual offending treatment program.

Decisions about assessment and treatment are best guided by current best practice recommendations validated by empirical studies in the field of forensic and correctional psychology. Advances in correctional and community-based treatment have shown that rehabilitation of individuals convicted of criminal offenses can be enhanced by following three key principles, widely known as the risk, need, and responsivity principles (RNR; Andrews \& Bonta, 2010) which broadly state that risk should be assessed with a validated tool and the level of intervention should be proportionate to an individual's risk level, with interventions that address criminogenic needs of the individuals, with programming based on cognitive social learning interventions and be tailored to an individual's personal characteristics. While the RNR principles provide a framework for the assessment and treatment of a variety of individuals committed offenses, they are of particular importance to individuals adjudicated of partner violence, who have elevated rates of treatment noncompletion and demonstrate minimal benefits from programs (Arias et al., 2013; Olver et al., 2011).

The existing research on the criminogenic needs of individuals who have perpetrated IPV suggests that they have the highest prevalence of criminogenic needs in comparison to other nonviolent and non-IPV individuals (Hilton \& Radatz, 2018; Stewart \& Power, 2014). This includes criminogenic needs featured in the central eight-a collection of the eight risk factors most commonly associated with recidivism (Andrews \& Bonta, 2010; Hilton \& Radatz, 2018). A review of dynamic risk factors for IPV indicates that substance abuse (particularly alcohol abuse) has garnered substantial evidence as an appropriate treatment target (Messing et al., 2016), with nearly 60\% of persons in IPV perpetration samples reporting problems with binge drinking (Langenderfer, 2013). The role of illicit drug use is less consistent, however, with some studies finding no significant association between IPV perpetration and illicit drug use (Cunradi et al., 2002) and others finding an association (Stuart et al., 2008). Furthermore, a profile of the criminogenic needs of federally incarcerated Canadian men attending a high-intensity IPV program confirmed that most had problems in all seven criminogenic needs (Stewart \& Power, 2014), particularly in family/marital circumstances and substance abuse. Those with IPV offenses also had more diverse criminal histories, self-reported mental health problems, and learning disabilities (i.e., responsivity issues), than those with non-IPV offenses. This is consistent with research that links enduring antisocial traits to individuals with IPV perpetration histories, particularly those with repeat perpetration (Harris et al., 2011). 
Harris and colleagues (2011) concluded that variables associated with IPV are anger, attitudes, hostility, jealousy, and substance abuse, and that these variables characterize an antisocial orientation.

Consistent with Stewart and Power (2014), Hilton and Radatz (2018) found that individuals with IPV offenses exhibited problems in six criminogenic need domains, with the most prevalent being employment/school circumstances, family/marital circumstances, and substance use. In addition, those with IPV offenses had significantly more criminogenic needs than those with either non-IPV violent offenses or nonviolent offenses, with the highest prevalence for every criminogenic need except for employment/school circumstances, and no group differences in noncriminogenic needs (i.e., major mental disorders and health problems). Other relevant treatment targets that have received less empirical support include attitudes supportive of the abuse of women, impulse control, poor social skills, association with antisocial peers who are supportive of the abuse of women, and past experience witnessing IPV as a child. One systematic review reported that emotional control problems and substance abuse in conjunction with conduct problems/antisocial behavior were among the psychological/behavioral factors significantly related to IPV perpetration history (Capaldi et al., 2012).

Unlike individuals with IPV offenses, individuals with sexual offending histories are more heterogeneous in terms of their offending behaviors (e.g., victim age, paraphilias, abnormal behaviors). Therefore, understanding their criminogenic needs vis-à-vis other groups of justice-involved individuals may be beneficial in understanding why there are explicit differences between those who perpetrate IPSV and IPV offenses-these differences may be better explained by our understanding of sexual offending behaviors. An early meta-analysis showed that several central eight risk factors were strongly related to sexual recidivism and included criminal history, younger age, and single marital status (Hanson \& Bussière, 1998). Specifically, some of the most robust predictors for sexual recidivism were related to antisocial orientation (i.e., antisocial personality pattern, antisocial traits, and history of rule violation; Hanson \& Morton-Bourgon, 2005). Individuals with general self-regulation difficulties (i.e., lifestyle instability or impulsivity) were more likely to sexually recidivate than those with stable lifestyles. In an update from Hanson and Morton-Bourgon's (2005) meta-analysis, Mann et al. (2010) found additional support for offense-supportive attitudes $(d=0.22)$, negative social influences $(d=0.26)$, noncompliance with supervision $(d=0.62)$, and violation of conditional release $(d=$ $0.50)$ as predictors of sexual recidivism. They further found that individuals who never married $(d=0.32)$, had conflicts in intimate relationships $(d=0.36)$, had employment instability $(d=0.22)$, and abused substances $(d=0.12)$ were more likely to sexually recidivate (Hanson \& Morton-Bourgon, 2005; Mann et al., 2010).

However, the literature makes it clear that evaluating reoffense risk based on the central eight alone is not suitable for individuals convicted of sexual offenses (Hanson et al., 2009). Two risk factors that are unique to sexual reoffense risk are sexual deviance 
(i.e., enduring interest to sexual activities that are illegal or socially inappropriate) and sexual preoccupation (i.e., an abnormally intense and prolonged interest in sexual activity that dominates psychological functioning; Hanson \& Morton-Bourgon, 2005). Mann and colleagues (2010) identified emotional congruence with children $(d=0.42)$ as a third risk factor, although this last risk factor is less relevant to those who perpetrate IPSV. Etzler and colleagues (2020) also found support for a three-factor structure in a sample of incarcerated Austrian people, with Antisociality and Sexual Deviance, but not Hypersexuality, being significant predictors of sexual recidivism. In accordance with the principles of RNR, these sexual-offense specific criminogenic needs must be targeted in treatment to effectively reduce sexual recidivism.

\section{The Current Study}

Revisiting the challenge of how to proceed with individuals who perpetrate IPSV and the binary decision of treating them predominantly as perpetrators of IPV or IPSV, further investigation is needed to understand the criminogenic needs that are most prevalent for this subset of individuals. The present study is an examination of the risk/need profiles of individuals who have perpetrated IPSV from a sample of police-reported IPV incidents. While sexual violence and IPV have separately received considerable attention in the literature, little research has specifically addressed IPSV (for an exception see, for example, Rettenberger \& Eher, 2013). Little is known about how those who perpetrate IPSV might differ in terms of risk and criminogenic needs from individuals who perpetrate IPV but do not sexually offend against their partners. As such, treatment targets for individuals who perpetrate IPSV may not address criminogenic needs that are specific to these individuals. Thus, the present study focuses primarily on criminogenic needs and compares the risk/need profiles of individuals who perpetrate IPSV with individuals who perpetrate IPV. It was hypothesized that the IPSV group would emerge as having a higher number of criminogenic and noncriminogenic needs than the IPV group. Though the above research is equivocal regarding the specific needs that may be more prevalent in one group, we did anticipate that members of the IPSV group would demonstrate higher scores on items that reflected sexual aggression.

\section{Method}

\section{Participants}

The original data sample comprised 300 incidents that were reported to a local police service during a 4-year period from 2010 to 2013 (see Jung \& Buro, 2017). Of the 300 incidents reported, 36 individuals were identified as having a current or former sexual offense against a partner. Of the remaining incidents, 36 individuals were chosen at random to serve as an IPV comparison group. This procedure was chosen to minimize any 
potential effects of variance heterogeneity, which can be exacerbated in research designs with unequal sample sizes (Howell, 2012). To be included in the sample, the incidents had to involve an identified person who perpetrated the offense and an identified person who was the complainant, who were either currently or formerly intimate partners, and the incident led to formal charges for direct violence (sexual or otherwise) or threat of direct violence to an intimate partner. Only incidents where a sole perpetrator was identified (i.e., excluded cases where violence was clearly bidirectional or where both parties were charged) and direct violence (sexual or otherwise) were included (e.g., excluded threats or criminal harassment). Due to the small number of accused females in the sample, only cases involving an accused adult male were included in this study's sample.

The sample of individuals who perpetrated IPSV $(n=36)$ were selected if sexual violence was reported at either the index incident or as a historical offense against the index complainant. This was determined by either the presence of formal charges or police reports with interview information that documented sexual violence through questions on an investigative report. The sample of individuals who perpetrated IPSV $(n=36)$ included all IPSV cases in the sample that met eligibility criteria.

The overall sample of 72 adult males used in our analyses had an average age at the time of the offense of 35.26 years $(S D=10.35$; ranging from 18.8 to 60.4$)$. The average length of the relationship between those who perpetrated the offenses and their victims was 66 months $(S D=79.4)$, with relationships ranging from one month to 29 years. Individuals who perpetrated the offenses tended to be slightly older than their victims by about one and a half years $(M=1.76, S D=8.25)$ and were predominantly male $(n=$ 63). Roughly half of individuals were Caucasian (51.4\%), followed by Indigenous (31.9\%), Black (5.6\%), and East Asian (5.6\%), with the remaining group encompassing diverse ancestries including Hispanic, Middle Eastern, and South Asian (5.6\%). Table 1 provides demographic information on the total sample and for each of the study groups.

\section{Measures}

A coding form was developed to operationalize the three broad groups of characteristics (offense, perpetrator features, and victim features). Items were included from an actuarial measure (ODARA; Hilton et al., 2010), a structured professional judgment measure (Spousal Assault Risk Assessment [SARA]; Kropp et al., 1995) and an investigative tool (Family Violence Investigative Report [FVIR]; Alberta Justice and Solicitor General, 2013).

The ODARA is a 13-item actuarial tool that was designed for use by police to determine risk of IPV recidivism among men who have already been identified by police as having committed at least one previous act and include items that assess the perpetrator's criminal history, features of prior or current domestic assaults, and victim circumstances (Hilton et al., 2010). The SARA (Kropp et al., 1995) is a 20-item tool developed for use with IPV offenders and contains items that assess criminal history, psychosocial 
Table 1

Sample Demographics

\begin{tabular}{|c|c|c|c|c|}
\hline \multirow[b]{2}{*}{ Variable } & \multicolumn{3}{|c|}{$M(S D)$ / Frequency $(\%)$} & \multirow[b]{2}{*}{$F / x^{2}$} \\
\hline & Overall & IPSV & IPV & \\
\hline Age (years) & $34.28(9.34)$ & $35.79(8.59)$ & $32.77(9.92)$ & 1.89 \\
\hline Accused-victim age difference (years) & $2.02(8.15)$ & $3.03(8.39)$ & $1.02(7.90)$ & 1.09 \\
\hline Relationship length (months) & $58.34(67.53)$ & $69.08(76.27)$ & $46.97(55.74)$ & 1.90 \\
\hline Ethnicity & & & & 2.72 \\
\hline Caucasian & $37(51.4 \%)$ & $15(41.7 \%)$ & $22(61.1 \%)$ & \\
\hline Indigenous & $23(31.9 \%)$ & $15(41.7 \%)$ & $8(22.2 \%)$ & \\
\hline Black & $5(6.9 \%)$ & $2(5.6 \%)$ & $3(8.3 \%)$ & \\
\hline East Asian & $3(4.2 \%)$ & $1(2.8 \%)$ & $2(5.6 \%)$ & \\
\hline Other & $4(5.6 \%)$ & $3(8.4 \%)$ & $1(2.8 \%)$ & \\
\hline Children shared & & & & 0.35 \\
\hline 0 & $44(62.0 \%)$ & $22(61.1 \%)$ & $22(62.9 \%)$ & \\
\hline 1 & $13(18.3 \%)$ & $6(16.7 \%)$ & $7(20.0 \%)$ & \\
\hline $2+$ & $14(19.7 \%)$ & $8(22.3 \%)$ & $6(17.2 \%)$ & \\
\hline ODARA score & $6.28(2.75)$ & $6.94(2.75)$ & $5.68(2.55)$ & 3.22 \\
\hline
\end{tabular}

Note. IPSV = Intimate Partner Sexual Violence; IPV = Intimate Partner Violence.

adjustment, spousal assault history, and characteristics of the current offense. While the ODARA and SARA share some overlap in items (such as prior violent incidents), the latter also assesses the accused's substance use, suicidal ideation, and attitudes that condone IPV, among other factors. A recent meta-analysis by van der Put and colleagues (2019) indicated that both instruments are among the most widely used by researchers, with the ODARA (AUC = .69) and SARA (AUC $=.64$ ) both predicting IPV better than chance. More specifically, in a sample of individuals convicted of sexually motivated intimate partner violence offenses, the ODARA yielded good predictive accuracy (AUC = .71) for the prediction of domestic violence recidivism (Rettenberger \& Eher, 2013). Lastly, the FVIR (Alberta Justice and Solicitor General, 2013) was created as an investigative and case management tool for police to gather critical information within 12 hours of the IPV incident-this interview schedule is currently used only in the region where the study was conducted.

\section{Other Dependent Variables}

To compare risk/need factors among the IPSV and IPV groups, we organized variables of interest into theoretically meaningful groups that aligned with the central eight risk/need 
factors (Andrews \& Bonta, 2010). These item clusters were used as proxies for risk factors found in the central eight as follows.

\section{Alcohol and Drug Composites}

Two items were dichotomously scored based on whether there was evidence that the accused used or consumed alcohol prior to the incident and whether it was deemed a factor in the violence. Two similar items pertaining to drugs formed the drug composite scale.

\section{Employment Composite}

Two dichotomously scored items were used to assess whether the accused was legally employed at the time of the index offense and the stability of their employment in the past year.

\section{Family/Marital Relations}

This consisted of items including past assault of family members (as measured by the SARA), recent relationship problems, current status of relationship (as measured by the FVIR), and whether the accused had a prior domestic incident (as measured by the ODARA). Items on the SARA are traditionally scored on a 3-point Likert-type scale (0-2), with higher scores demonstrating greater severity. However, to allow for each item to be afforded equal weight in the composite (i.e., to be similar in scoring to the dichotomous ODARA and FVIR items), these scores were transformed to values of $0,0.5$, and 1 .

\section{Mental Health}

Presence of an anxiety disorder, prior suicide attempts, and use of psychotropic medication were included in a 6-item measure of the accused's mental health status. All items were scored dichotomously.

\section{Offense-Supportive Attitudes}

A measure of procriminal attitudes was created, consisting of two items (16 \& 17) from the SARA which measure minimization/denial of IPV and attitudes that condone IPV, respectively. These were also transformed from their original scale to a 3-point 0-1 scale, with higher values reflecting greater IPV-supportive attitudes. Due to missing data, an average score was computed for each individual.

\section{Violent Criminal History Composite}

This was comprised of six items, including whether the accused had prior weapons arrests, whether they had prior IPV offenses with other partners, and any arrests or convictions for uttering threats. These were all scored dichotomously. 


\section{Criminal History Composite}

This included all six of the violent criminal history composite items including three more pertaining to juvenile delinquency, supervision violations, and substance-related arrests. The additional three items were also scored dichotomously.

\section{Sexual Aggression}

Although this is not a component of the central eight, given that it is a major predictor of sexual offending, we created a measure of sexual aggression comprised of two items: 1) past sexual assault/jealousy and 2) prior sexual arrests/convictions. As one item was taken from the SARA, its scoring was transformed similar to the above-mentioned items.

\section{Aggregate Central Eight}

An overall measure was created of variables related to the central eight (alcohol use, drug use, criminal history, employment, family/marital, and attitudes) by averaging the average scores in each composite, ensuring that each variable was equally weighted. Thus, scores ranged from 0 -1, with high scores indicating a greater need in central eight related domains.

A list of the variables included in each composite with a brief operationalization of each can be found in the Appendix. These composites contained items that had been coded in a binary manner reflecting their presence or absence and were then summed in the composite after each component had been evenly weighted.

\section{Procedure}

Of the initial sample $(n=300), 36$ were identified as having committed or having been accused of committing a sexual offense against an intimate partner, which comprised the IPSV group. Out of the remaining 264 individuals, 36 were randomly selected to form the IPV comparison group, resulting in a total subsample of 72 perpetrators. Using a coding form, police file documentation was reviewed and coded by the third author. The primary researcher is a doctoral-level clinician who served as the primary rater in this study and had previously completed training on the ODARA (i.e., online, restricted-access training program, called ODARA 101) and the SARA (i.e., in-person workshop). A research assistant with limited access to electronic police documents coded items on the ODARA and the SARA for a subset of the data $(n=20)$ after data collection was completed. Interrater reliability was analyzed using a single-measurement, consistency-agreement, two-way mixed effects model. Our results indicated that interrater reliability was good for overall score of the ODARA (ICC $=.90 ; 95 \% \mathrm{CI}=.75-.96$ ) and the SARA (ICC $=.84 ; 95 \% \mathrm{CI}=.62-.93$ ). Given that the FVIR tool was used by police officers at the time of the investigation, we were unable to examine interrater reliability for the use of the FVIR. 


\section{Data Analytic Strategy}

Correlational analyses were used to determine the strength of association between the above variables. Then, to compare the composites between the two groups, analysis of covariance (ANCOVA) was conducted using a bootstrap estimate approach with 1,000 resamples. Although there were no statistically significant differences in age between the two groups, age was significantly associated with some measures and with some variables (i.e., family/marital, alcohol, and employment composites; see Table 2), and was entered as a covariate to parse out its effects. An examination of the similarities and differences in risk composites between the two groups is described hereafter, including measures of effect size, interpreted according to Cohen's (1992) conventions that recommend $0.2,0.5$, and 0.8 as the benchmarks for small, medium, and large effect sizes, respectively.

Table 2

Correlations Between Risk/Need Composites

\begin{tabular}{|c|c|c|c|c|c|c|c|c|c|c|c|}
\hline Variable & 1 & 2 & 3 & 4 & 5 & 6 & 7 & 8 & 9 & 10 & 11 \\
\hline 1. Age & - & & & & & & & & & & \\
\hline 2. Alcohol use & -.189 & - & & & & & & & & & \\
\hline 3. Drug use & -.054 & -.029 & - & & & & & & & & \\
\hline 4. Employment instability & .098 & $-.270^{*}$ & .051 & - & & & & & & & \\
\hline 5. Family/marital relations & $.287^{*}$ & -.035 & -.023 & .042 & - & & & & & & \\
\hline 6. Mental health & .009 & $-.265^{*}$ & .215 & .136 & .166 & - & & & & & \\
\hline 7. Procriminal attitudes & .012 & .036 & .251 & .043 & .058 & -.077 & - & & & & \\
\hline 8. Violent criminal history & .110 & .023 & $.276^{*}$ & .012 & $.513^{* *}$ & .000 & .260 & - & & & \\
\hline 9. General criminal history & .088 & .116 & .176 & -.058 & $.441^{* *}$ & -.056 & .296 & $.941^{* *}$ & - & & \\
\hline 10. Sexual aggression & .006 & -.009 & $.243^{*}$ & .229 & .160 & -.130 & -.180 & $.557^{* *}$ & $.439^{* *}$ & - & \\
\hline 11. Central eight & -.022 & $.546^{* *}$ & $.515^{*}$ & .166 & $.442^{* *}$ & -.010 & $.508^{* *}$ & $.612^{* *}$ & $.600^{* *}$ & $.393^{* *}$ & - \\
\hline
\end{tabular}

Note. $n$ ranged from 36 to 72 . Please contact first author if you require the $n$ for a specific correlational analysis. ${ }^{*} p<.05 .{ }^{* *} p<.01$.

\section{Results}

\section{Correlational Analyses}

Table 2 reports the correlational analyses between the variables of interest. Interestingly, many of the variables did not evidence statistically significant associations with one another. However, higher scores on the family/marital relations composite (indicative of greater problems in these relationships) were significantly associated with both general and violent criminal history. With respect to the substance use composites, each was associated with different variables. For instance, drug use was associated with sexual aggression and violent criminal history, while alcohol use was not. Alcohol use did emerge 
as the only variable to be significantly associated with the mental health composite, albeit with fewer mental health concerns.

\section{IPV and IPSV Comparisons on Domains of Risk and Need}

Of note, the current sample scored higher on the ODARA than those in its validation sample $(M=6.41, S D=2.72$, and $M=2.89, S D=2.14$, respectively). However, these higher scores are common when using data from police records (e.g., Ulmer, 2015).

A series of ANCOVAs were conducted, with age entered as a covariate, to compare accused IPV and IPSV offender scores on the study composites (see Table 3). No significant differences emerged for the alcohol use composite, with both groups averaging roughly one indicator that alcohol was either ingested or a factor in the violence. Drug use appeared to be less common, although the IPSV group did score higher than the IPV group indicating more drug use (at least during the time surrounding the violence).

Table 3

Comparison of IPSV and IPV Perpetrator Composite Scores

\begin{tabular}{|c|c|c|c|c|c|c|c|c|}
\hline \multirow[b]{2}{*}{ Measure } & \multicolumn{2}{|c|}{ IPSV } & \multicolumn{2}{|r|}{ IPV } & \multirow[b]{2}{*}{$F$} & \multirow[b]{2}{*}{$p$} & \multirow[b]{2}{*}{$\eta^{2}$} & \multirow[b]{2}{*}{$d$} \\
\hline & $n$ & $M(S D)$ & $n$ & $M(S D)$ & & & & \\
\hline Alcohol use & 36 & $1.03(0.97)$ & 36 & $1.47(0.88)$ & 3.26 & .075 & .05 & 0.42 \\
\hline Drug use & 36 & $0.39(0.80)$ & 36 & $0.08(0.37)$ & 4.73 & .033 & .06 & 0.51 \\
\hline Employment instability & 36 & $1.11(0.46)$ & 33 & $1.00(0.43)$ & 0.78 & .380 & .01 & 0.21 \\
\hline Family/marital relations & 31 & $2.39(0.89)$ & 31 & $1.76(1.06)$ & 4.60 & .036 & .07 & 0.54 \\
\hline Mental health & 34 & $1.59(1.76)$ & 35 & $0.71(1.13)$ & 6.12 & .016 & .09 & 0.60 \\
\hline Procriminal attitudes & 17 & $0.47(0.36)$ & 19 & $0.63(0.23)$ & 2.59 & .117 & .07 & 0.54 \\
\hline Violent criminal history & 32 & $3.03(1.67)$ & 34 & $2.24(1.52)$ & 3.54 & .065 & .05 & 0.46 \\
\hline General criminal history & 31 & $4.35(2.35)$ & 34 & $3.62(2.27)$ & 1.36 & .248 & .02 & 0.29 \\
\hline Sexual aggression & 36 & $0.76(0.74)$ & 36 & $0.39(0.49)$ & 6.42 & .014 & .09 & 0.60 \\
\hline Central eight & 36 & $0.48(0.16)$ & 36 & $0.43(0.13)$ & 1.70 & .196 & .03 & 0.30 \\
\hline
\end{tabular}

Note. Statistically significant $(p<.05)$ findings are bolded. IPSV = Intimate Partner Sexual Violence; IPV = Intimate Partner Violence.

In addition to an increased propensity to use illicit substances, those accused of IPSV also had significantly more mental health issues than their counterparts. Scores on the composite indicate a medium effect size for the IPSV group, who had one more mental health concern than those accused of non-sexual intimate partner violence. Specifically, anxiety disorders were found exclusively among the IPSV group (16.7\% prevalence vs. $0 \%$ ), as well as higher rates of reported mood disorders (33.3\% prevalence vs. $11.4 \%$ ). The IPSV group also evidenced a medium effect size on the family/marital relations index, with higher scores indicative of a more extensive history of adverse relations with family members and romantic partners. 
In line with the finding that individuals accused of IPSV demonstrate more turbulent relationships with those closest to them, this group also had a more pervasive history of committing violent crimes. A large proportion of both groups were involved in a violent crime, which made up $70 \%$ and $62 \%$ of all crimes measured in the criminal history index for IPSV and IPV offenders, respectively. In addition to violent offenses, members of the IPSV group also had a significantly more extensive history of sexual aggression, indicating that for many, their current status is a repeated behavior. Both groups appeared to have similar levels of employment instability, with composite averages indicating that many were either not legally employed or had recently experienced employment instability at the time of the offense. Further, there were no significant differences between the two groups in the procriminal attitudes held.

To determine whether any of the variables could uniquely predict group membership, a binary logistic regression was used, entering all variables into the model simultaneous$\mathrm{ly}^{1}$. Overall, the entire model predicted group membership correctly in $76 \%$ of cases. As found in Table 4, the sexual aggression composite significantly predicted membership in the IPSV group. Regarding noncriminogenic needs, mental health problems also significantly predicted group membership.

\section{Table 4}

Prediction of Group Membership

\begin{tabular}{|c|c|c|c|c|c|}
\hline Measure & $\boldsymbol{B}$ & $S E$ & $p$ & $\operatorname{Exp}(B)$ & $95 \% \mathrm{CI}$ \\
\hline Alcohol use & 0.347 & 0.419 & .408 & 1.415 & $0.622,3.217$ \\
\hline Drug use & -1.717 & 1.218 & .159 & .180 & $0.016,1.955$ \\
\hline Employment instability & 1.341 & 1.012 & .185 & 3.822 & $0.526,27.781$ \\
\hline Family/marital relations & -0.892 & 0.520 & .086 & .410 & $0.148,1.135$ \\
\hline Mental health & -0.704 & 0.307 & .022 & .495 & $0.271,0.903$ \\
\hline Violent criminal history & 0.335 & 0.869 & .700 & 1.398 & $0.255,7.676$ \\
\hline General criminal history & -0.052 & 0.515 & .920 & .950 & $0.346,2.607$ \\
\hline Sexual aggression & -1.953 & 0.781 & .012 & .142 & $0.031,0.656$ \\
\hline \multicolumn{6}{|l|}{ Model summary } \\
\hline Cox \& Snell $R^{2}$ & & & .381 & & \\
\hline Nagelkerke $R^{2}$ & & & .508 & & \\
\hline
\end{tabular}

Note. $N=55$. Statistically significant $(p<.05)$ findings are bolded.

1) Due to missing data, procriminal attitudes were not included in the regression model. 


\section{Discussion}

\section{Brief Summary of Results}

In response to the limited research, that has investigated IPSV, we set out to compare the risk/need profiles of IPSV and IPV perpetrators by creating theoretically meaningful risk composites as proxies for a number of the central eight risk/need areas posited by Andrews and Bonta (2010). Results indicated that IPSV perpetrators have higher criminogenic needs overall than the IPV perpetrator group. We found statistically significant group differences in several criminogenic need domains; the risk/need profiles of IPSV perpetrators were characterized by increased issues with substance abuse, family and marital instability, and sexual aggression than IPV perpetrators.

In fact, IPSV perpetrators had a higher prevalence for every criminogenic need except employment instability and alcohol use, which was similar between the two groups. IPSV perpetrators also had significantly more pervasive histories of sexual aggression than IPV perpetrators. Regarding noncriminogenic needs, IPSV perpetrators also evidenced more mental health concerns, particularly anxiety disorders. This highlights the importance of incorporating noncriminogenic needs when differentiating the two groups. Specifically, only these mental health concerns as well as sexual aggression significantly predicted group membership in a logistic regression.

\section{Implications}

That individuals with IPSV offenses demonstrate more severe risk/need profiles may have important implications for policing and intervention practices. IPSV is likely underreported, even in our sample. A previous study found that $44 \%$ of women recruited at the scene of police-investigated IPV incidents reported experiencing IPSV, with $17.36 \%$ reporting sexual abuse and $26.62 \%$ reporting forced sex (Messing et al., 2014). Further, another study reported that a significant number of men (53\%) enrolled in a program for partner abuse had engaged in sexual violence against their partners, though few (8\%) self-identified their actions as sexually abusive (Bergen \& Bukovec, 2006).

This underreporting is particularly troubling given research that has found that sexual assaults committed by intimate partners are characterized by more coercion, physical trauma, and injury severity than those committed by strangers or acquaintances (Culbertson \& Dehle, 2001; Mahoney, 1999; Stermac et al., 2006). This concern is exacerbated by results that demonstrate an increased risk of intimate partner homicide when sexually assaultive behavior is present in IPV (Campbell et al., 2007). These staggering numbers suggest that more action is required in assessing IPSV in policing and in targeting sexual aggression and sexual behavior as criminogenic needs in intervention programs.

As gatekeepers of the criminal justice system, police have considerable discretion as it relates to perpetrator arrest and case forwarding decisions (Tasca et al., 2013). Thus, 
at this gatekeeping level, results of this study lend support for increased monitoring of sexually assaultive behavior with intimate partners when police respond to an IPV call. Though sexual assault of an intimate partner is queried in some jurisdictions using some regional interview checklists and actuarial risk measures, it cannot be assumed that victims would voluntarily report this behavior even when physical abuse by their partner is revealed (Cox, 2016). In fact, research has shown there is a longer delay in reporting sexual violence in intimate relationships than other forms of sexual and nonsexual violence (Jung et al., 2020). It therefore may be important to broaden the scope of questions asked about the perpetrator's use of sexual violence. Continuing to orient police to evidence-based risk factors for future violence is vital, and applications of IPV risk assessment measures (some of which include questions about sexual assault) are increasingly seen in policing (e.g., ODARA; Hilton et al., 2010).

There are also several potential implications at the level of IPV intervention programming. The characteristics of individuals with IPSV offenses in this sample-which include more extensive history of sexual aggression, greater substance abuse, relationship instability, and mental health concerns-suggest that IPSV perpetrators require higher intensity of intervention. Though mental health concerns are considered noncriminogenic, these concerns may interfere with treatment and require stabilization before criminogenic needs can be addressed. Given the higher prevalence of mental health concerns with IPSV perpetrators in this sample, addressing and stabilizing mental health concerns may be even more crucial. In addition to having more criminogenic needs (Hilton \& Radatz, 2018), individuals with IPV offenses pose a challenge in meeting treatment needs, with higher rates of treatment attrition and higher prevalence of mental health concerns (Olver et al., 2011; Stewart \& Power, 2014). The greater prevalence and severity of criminogenic needs in this study's IPSV sample suggests that these same treatment concerns would be present, and may even be more challenging when engaging individuals with a history of IPSV perpetration.

\section{Conclusions, Limitations, and Future Directions}

To our knowledge, this is the first study to examine the risk/need profiles of IPSV perpetrators and can draw two tentative conclusions. First, when compared to individuals with IPV offenses, those with IPSV offenses are higher risk, have more criminogenic needs, and have noncriminogenic needs that may require attention. Second, increased assessment and intervention efforts may be required at the policing and correctional level with individuals who have perpetrated IPSV, as their rate and severity of recidivism risk may be higher. These findings provide preliminary support for the importance of increased intervention with individuals with IPSV offenses.

This study is bound by certain limitations, namely the small sample size which hindered our ability to analyze other categorical information, such as marital status and ethnicity. Additionally, this study utilized secondary data, and as such, relevant perpetra- 
tor information for some variables was either missing (e.g., procriminal attitudes) or not collected in police reports (e.g., antisocial associates), leaving some crucial components of the central eight uninvestigated. Further, as the sample consisted of only men, it was not possible to examine differences across gender. Such comparisons are needed as the differences between the criminogenic needs of women and men who perpetrate IPV is unclear (Mackay et al., 2018; Wielinga et al., 2017).

This study was conducted with an accused population of IPV and IPSV perpetrators who had come into contact with law enforcement. Future research would do well to investigate IPSV in a convicted population, determining whether risk/need profiles differ between those who receive custodial sentencing and those who receive probation or other less restrictive sanctions. It is also pertinent to compare the risk/need profiles of IPSV and other sexually violent offenders to determine if the risk/need profiles of IPSV perpetrators fit better with the latter group than with IPV perpetrators, or whether a separate IPSV category is warranted. Given the lack of efficacy in some IPV treatment, investigating whether treatment is less effective for the subgroup of offenders who have sexually assaulted their intimate partners warrants further inquiry.

The sparse empirical focus on IPSV prevents an evidence-based discussion about the potentially unique risk/need profiles of IPSV perpetrators. It is hoped that the present study facilitates this discussion and encourages researchers to dedicate more efforts to understanding individuals with a history of sexual violence against a partner. The importance of acknowledging and documenting sexual violence in intimate relationships and advocating for appropriate prevention and intervention strategies cannot be underestimated, as the well-known enduring nature of intimate partner abuse places individuals at significant risk and adversely effects society as a whole. Based on the results of this study and the apparent differences between the groups on a number of criminogenic need domains, it is recommended that risk assessments encompassing central eight variables be used while their utility in predicting IPV recidivism continues to be evaluated.

Funding: The authors have no funding to report.

Competing Interests: The authors have declared that no competing interests exist.

Acknowledgments: The authors express deep appreciation to the Edmonton Police Services for their support of this research. The points of view expressed in this article do not necessarily represent the views of the Edmonton Police Service.

Data Availability: Due to confidentiality agreements with the police service whose records comprise this dataset and the potential for this dataset to contain confidential information, we are unable to make the data publicly available. 


\section{Supplementary Materials}

The following Supplementary Materials are available (for access see Index of Supplementary Materials below):

- Supplemental file A (coding syntax): This file contains the SPSS coding syntax for the composites used in the analyses. Note that the AttitudeAverage composite is not included, as this had to be hand calculated due to SPSS' inability to calculate an average with missing data.

- Supplemental file B (analysis syntax): This file contains the SPSS analysis syntax for the correlations, ANCOVAs, and binary logistic regression analyses mentioned in the manuscript.

\section{Index of Supplementary Materials}

Sparks, B., Wielinga, F., Jung, S., \& Olver, M. (2020). Supplementary materials to "Recidivism risk and criminogenic needs of individuals who perpetrated intimate partner sexual violence offenses" [Coding and analysis syntax]. PsychOpen. https://doi.org/10.23668/psycharchives.3080

\section{References}

Alberta Justice and Solicitor General. (2013). Domestic violence police guidelines. Edmonton, AB, Canada: Author.

Andrews, D. A., \& Bonta, J. (2010). Rehabilitating criminal justice policy and practice. Psychology, Public Policy, and Law, 16(1), 39-55. https://doi.org/10.1037/a0018362

Arias, E., Arce, R., \& Vilariño, M. (2013). Batterer intervention programmes: A meta-analytic review of effectiveness. Intervención Psicosocial, 22(2), 153-160. https://doi.org/10.5093/in2013a18

Bagwell-Gray, M. E., Messing, J. T., \& Baldwin-White, A. (2015). Intimate partner sexual violence: A review of terms, definitions, and prevalence. Trauma, Violence \& Abuse, 16(3), 316-335. https://doi.org/10.1177/1524838014557290

Bergen, R. K., \& Bukovec, P. (2006). Men and intimate partner rape: Characteristics of men who sexually abuse their partner. fournal of Interpersonal Violence, 21(10), 1375-1384. https://doi.org/10.1177/0886260506291652

Campbell, J. C., Glass, N. E., Sharps, P. W., Laughon, K., \& Bloom, T. (2007). Intimate partner homicide: Review and implications of research and policy. Trauma, Violence \& Abuse, 8(3), 246-269. https://doi.org/10.1177/1524838007303505

Capaldi, D. M., Knoble, N. B., Shortt, J. W., \& Kim, H. K. (2012). A systematic review of risk factors for intimate partner violence. Partner Abuse, 3(2), 231-280.

https://doi.org/10.1891/1946-6560.3.2.231

Cohen, J. (1992). A power primer. Psychological Bulletin, 112(1), 155-159. https://doi.org/10.1037/0033-2909.112.1.155

Cox, P. (2016). Violence against women: Additional analysis of the Australian bureau of statistics' Personal Safety Survey, 2012 (ANDROWS Horizons: 01.01/2016 Rev. ed.). Australia's National Research Organisation for Women's Safety Limited (ANDROWS). 
Culbertson, K. A., \& Dehle, C. (2001). Impact of sexual assault as a function of perpetrator type. Journal of Interpersonal Violence, 16(10), 992-1007. https://doi.org/10.1177/088626001016010002

Cunradi, C. B., Caetano, R., \& Schafer, J. (2002). Alcohol-related problems, drug use, and male intimate partner violence severity among US couples. Alcoholism, Clinical and Experimental Research, 26(4), 493-500. https://doi.org/10.1111/j.1530-0277.2002.tb02566.x

Eby, K. K., Campbell, J. C., Sullivan, S. M., \& Davidson, W. S., II. (1995). Health effects of experiences of sexual violence for women with abusive partners. Health Care for Women International, 16(6), 563-576. https://doi.org/10.1080/07399339509516210

Etzler, S., Eher, R., \& Rettenberger, M. (2020). Dynamic risk assessment of sexual offenders: Validity and dimensional structure of the Stable-2007. Assessment, 27(4), 822-839. https://doi.org/10.1177/1073191118754705

Hanson, R. K., Bourgon, G., Helmus, L., \& Hodgins, S. (2009). The principles of effective correctional treatment also apply to sexual offenders: A meta-analysis. Criminal fustice and Behavior, 36, 865-891. https://doi.org/10.1177/0093854809338545

Hanson, R. K., \& Bussière, M. T. (1998). Predicting relapse: A meta-analysis of sexual offender recidivism studies. Journal of Consulting and Clinical Psychology, 66(2), 348-362. https://doi.org/10.1037/0022-006X.66.2.348

Hanson, R. K., \& Morton-Bourgon, K. E. (2005). The characteristics of persistent sexual offenders: A meta-analysis of recidivism studies. fournal of Consulting and Clinical Psychology, 73(6), 1154-1163. https://doi.org/10.1037/0022-006X.73.6.1154

Harris, G. T., Hilton, N. Z., \& Rice, M. E. (2011). Explaining the frequency of intimate partner violence by male perpetrators: Do attitude, relationship, and neighborhood variables add to antisociality? Criminal fustice and Behavior, 38(4), 309-331.

https://doi.org/10.1177/0093854810397449

Hilton, N. Z., Harris, G. T., \& Rice, M. E. (2010). Risk assessment for domestically violent men: Tools for criminal justice, offender intervention, and victim services. Washington, DC, USA: American Psychological Association. https://doi.org/10.1037/12066-000

Hilton, N. Z., \& Radatz, D. L. (2018). The criminogenic and noncriminogenic treatment needs of intimate partner violence offenders. International fournal of Offender Therapy and Comparative Criminology, 62(11), 3247-3259. https://doi.org/10.1177/0306624X17740015

Howell, D. C. (2012). Statistical methods for psychology (8th ed.). Belmont, CA, USA: Wadsworth Publishing.

Jung, S., \& Buro, K. (2017). Appraising risk for intimate partner violence in a police context. Criminal fustice and Behavior, 44(2), 240-260. https://doi.org/10.1177/0093854816667974

Jung, S., Faitakis, M., \& Cheema, H. (2020). A comparative profile of intimate partner sexual violence. fournal of Sexual Aggression. Advance online publication. https://doi.org/10.1080/13552600.2020.1722268

Keighley, K. (2017). Police-reported crime statistics in Canada, 2016 (Juristat; Statistics Canada catalogue no. 85-002-X). Retrieved from https://www150.statcan.gc.ca/n1/pub/85-002-x/2017001/article/54842-eng.htm 
Kropp, P. R., Hart, S. D., Webster, C. W., \& Eaves, D. (1995). Manual for the Spousal Assault Risk Assessment Guide (2nd ed.). British Columbia Institute on Family Violence. https://doi.org/10.1037/t38062-000

Langenderfer, L. (2013). Alcohol use among partner violent adults: Reviewing recent literature to inform intervention. Aggression and Violent Behavior, 18(1), 152-158. https://doi.org/10.1016/j.avb.2012.11.013

Mackay, J. L., Bowen, E., Walker, K., \& O’Doherty, L. (2018). Risk factors for female perpetrators of intimate partner violence within criminal justice settings: A systematic review. Aggression and Violent Behavior, 41, 128-146. https://doi.org/10.1016/j.avb.2018.06.004

Mahoney, P. (1999). High rape chronicity and low rates of help-seeking among wife rape survivors in a nonclinical sample. Violence Against Women, 5(9), 993-1016. https://doi.org/10.1177/10778019922181590

Mann, R. E., Hanson, R. K., \& Thornton, D. (2010). Assessing risk for sexual recidivism: Some proposals on the nature of psychologically meaningful risk factors. Sexual Abuse, 22(2), 191-217. https://doi.org/10.1177/1079063210366039

McFarlane, J., Malecha, A., Watson, K., Gist, J., Batten, E., Hall, I., \& Smith, S. (2005). Intimate partner sexual assault against women: Frequency, health consequences, and treatment outcomes. Obstetrics and Gynecology, 105(1), 99-108. https://doi.org/10.1097/01.AOG.0000146641.98665.b6

Messing, J. T., Mendoza, N. S., \& Campbell, J. C. (2016). Alcohol use and latent profiles of intimate partner violence. Fournal of Social Work Practice in the Addictions, 16(1-2), 160-175. https://doi.org/10.1080/1533256X.2016.1164058

Messing, J. T., Thaller, J., \& Bagwell, M. (2014). Factors related to sexual abuse and forced sex in a sample of women experiencing police-involved intimate partner violence. Health \& Social Work, 39(3), 181-191. https://doi.org/10.1093/hsw/hlu026

Olver, M. E., Stockdale, K. C., \& Wormith, J. S. (2011). A meta-analysis of predictors of offender treatment attrition and its relationship to recidivism. Journal of Consulting and Clinical Psychology, 79(1), 6-21. https://doi.org/10.1037/a0022200

Rettenberger, M., \& Eher, R. (2013). Actuarial risk assessment in sexually motivated intimatepartner violence. Law and Human Behavior, 37(2), 75-86. https://doi.org/10.1037/b0000001

Rotenburg, C. (2017). Police-reported sexual assaults in Canada, 2009 to 2014: A statistical profile (Juristat; Statistics Canada Catalogue no. 85-002-X). Retrieved from https://www150.statcan.gc.ca/n1/pub/85-002-x/2017001/article/54866-eng.htm

Stermac, L., Del Bove, G., Brazeau, P., \& Bainbridge, D. (2006). Patterns in sexual assault violence as a function of victim perpetrator degree of relatedness. fournal of Aggression, Maltreatment \& Trauma, 13(1), 41-58. https://doi.org/10.1300/J146v13n01_03

Stewart, L. A., \& Power, J. (2014). Profile and programming needs of federal offenders with histories of intimate partner violence. fournal of Interpersonal Violence, 29(15), 2723-2747. https://doi.org/10.1177/0886260514526059 
Stuart, G. L., Temple, J. R., Follansbee, K. W., Bucossi, M. M., Hellmuth, J. C., \& Moore, T. M. (2008). The role of drug use in a conceptual model of intimate partner violence in men and women arrested for domestic violence. Psychology of Addictive Behaviors, 22(1), 12-24.

https://doi.org/10.1037/0893-164X.22.1.12

Tasca, M., Rodriguez, N., Spohn, C., \& Koss, M. P. (2013). Police decision making in sexual assault cases: Predictors of suspect identification and arrest. fournal of Interpersonal Violence, 28(6), 1157-1177. https://doi.org/10.1177/0886260512468233

Ulmer, J. C. (2015). The Ontario Domestic Assault Risk Assessment (ODARA): A validation and comparison study for an Oregonian law enforcement agency (Doctoral dissertation, George Fox University, Newberg, OR, USA). Retrieved from https://digitalcommons.georgefox.edu/psyd/177 van der Put, C. E., Gubbels, J., \& Assink, M. (2019). Predicting domestic violence: A meta-analysis on the predictive validity of risk assessment tools. Aggression and Violent Behavior, 47(JulyAugust), 100-116. https://doi.org/10.1016/j.avb.2019.03.008

Wielinga, F., Lupse, D., \& Jung, S. (2017, June 7-10). Female perpetrators of intimate partner violence. In K. Nunes, N. Z. Hilton, M. Olver, \& S. Jung (Chairs), Intimate partner violence: Examining elements of the risk, need, and responsivity principles. Symposium conducted at the 78th Annual Meeting of the Canadian Psychological Association, Toronto, ON, Canada.

Wong, S., Olver, M. E., Nicholaichuk, T. P., \& Gordon, A. (2003). The Violence Risk Scale: Sexual Offender version (VRS-SO). Saskatoon, SK, CA: Regional Psychiatric Centre and University of Saskatchewan.

\section{Appendix}

\begin{tabular}{lcl}
\hline Composite & \# of items & Items \\
\hline Alcohol use & 2 & $\begin{array}{l}\text { Evidence accused used/consumed alcohol } \\
\text { Alcohol was a factor in the violence }\end{array}$ \\
\hline Drug use & 2 & $\begin{array}{l}\text { Evidence accused used/consumed drugs } \\
\text { Drugs were a factor in the violence }\end{array}$ \\
\hline Employment instability & 2 & $\begin{array}{l}\text { Currently legally employed } \\
\text { Unstable employment prior 12 months (FVIR \#15) }\end{array}$ \\
\hline Family/marital relations & 4 & $\begin{array}{l}\text { Past assault of family members (SARA \#1) } \\
\text { Recent relationship problems (SARA \#4) } \\
\text { Relationship status (FVIR \#8) } \\
\text { Prior domestic incident (ODARA \#1) }\end{array}$ \\
& & $\begin{array}{l}\text { History of psychological problems } \\
\text { Presence of mood disorder } \\
\text { Presence of anxiety disorder } \\
\text { Presence of psychotic disorder } \\
\text { Prior suicide attempts } \\
\text { Use of psychotropic medication }\end{array}$ \\
& 6 &
\end{tabular}




\begin{tabular}{|c|c|c|}
\hline Composite & $\#$ of items & Items \\
\hline Procriminal attitudes & 2 & $\begin{array}{l}\text { Minimization/denial of IPV (SARA \#16) } \\
\text { Attitudes that condone IPV (SARA \#17) }\end{array}$ \\
\hline Violent criminal history & 6 & $\begin{array}{l}\text { Prior violent arrests/convictions } \\
\text { Uttering threat arrests/convictions } \\
\text { Prior IPV with other partners } \\
\text { Prior sexual offenses } \\
\text { Prior weapons arrests } \\
\text { First IPV against current partner }\end{array}$ \\
\hline General criminal history & 9 & $\begin{array}{l}\text { Juvenile delinquency } \\
\text { Prior violent arrests/convictions } \\
\text { Uttering threat arrests/convictions } \\
\text { Prior IPV with other partners } \\
\text { Prior sexual offenses } \\
\text { Prior supervision violations } \\
\text { Prior substance-related arrests } \\
\text { Prior weapons arrests } \\
\text { First IPV against current partner }\end{array}$ \\
\hline Sexual aggression & 2 & $\begin{array}{l}\text { Past sexual assault/jealousy (SARA \#12) } \\
\text { Prior sexual arrest/convictions }\end{array}$ \\
\hline Central eight & 6 & $\begin{array}{l}\text { Items from alcohol/drug use, criminal history, employment, family/ } \\
\text { marital, and attitudes composites (averaged for even weighting) }\end{array}$ \\
\hline
\end{tabular}

Sexual Offending: Theory, Research, and Prevention is the official journal of the International Association for the Treatment of Sexual Offenders (IATSO).

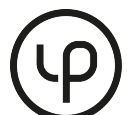

leibniz-psychology.org

PsychOpen GOLD is a publishing service by Leibniz Institute for Psychology Information (ZPID), Germany. 